\title{
AEROBIC BACTERIOLOGY OF CHRONIC SUPPURATIVE OTITIS MEDIA: OUR EXPERIENCE
}

Mahesh V. Kattimani1 ${ }^{1}$, Shweta Anand ${ }^{2}$

\section{HOW TO CITE THIS ARTICLE:}

Mahesh V. Kattimani, Shweta Anand. "Aerobic Bacteriology of Chronic Suppurative Otitis Media: Our Experience". Journal of Evolution of Medical and Dental Sciences 2015; Vol. 4, Issue 67, August 20;

Page: 11686-11694, DOI: 10.14260/jemds/2015/1685

ABSTRACT: Chronic Suppurative Otitis Media (CSOM) is a condition of the middle ear that is characterized by persistent or recurrent discharge through a chronic perforation of the tympanic membrane from the middle ear cleft. Untreated cases of Chronic Suppurative Otitis Media can result in a broad range of complications like mastoiditis, labyrinthitis, facial nerve paralysis and serious intracranial complications. In this study an attempt is made to know the aerobic bacteriology of Chronic Suppurative Otitis Media, with antimicrobial susceptibility testing of the bacterial isolates. The present prospective study was carried out on 50 patients presenting with Chronic Suppurative Otitis Media between January 2014 to December 2014 in the department of E.N.T, Basaveshwara Medical College Hospital and Research Centre, Chitradurga. The most common bacteria in Chronic Suppurative Otitis Media in this study was Pseudomonas aeruginosa (62\%) followed by Staphylococcus aureus (22\%). Gentamicin was the most sensitive (100\%) antibiotic against Pseudomonas aeruginosa followed by Amikacin (96.77\%). Ceftriaxone and Gentamicin were the most sensitive (100\%) antibiotic against Staphylococcus aureus followed by Amikacin (90.9\%)

KEYWORDS: Chronic suppurative otitis media, Antibiotic susceptibility, Pseudomonas, Gentamicin.

INTRODUCTION: Chronic Suppurative Otitis Media is one of the most common diseases of the ear in childhood. The hearing loss associated with Chronic Suppurative Otitis Media leads to educational backwardness in children that is well recognized mainly by the otolaryngologists and also by paediatricians and educators.

Chronic Suppurative Otitis Media is a disease well known for its persistence and recurrence despite of treatment given. Chronic Suppurative Otitis Media is a long standing inflammatory disease affecting mucoperiosteal lining of middle ear presenting as aural discharge with variable degree of hearing loss. Sometimes, the course of disease is prolonged which leads to irreversible local destruction of mucosa of the middle ear cleft and underlying bone and may lead to serious intra and or extra cranial complications.

The disease is mainly classified into two types: Tubo-tympanic and Attico-antral depending upon whether the disease process affects the pars-tensa or pars-flaccida of the tympanic membrane. Pus culture in both types of Chronic Suppurative Otits Media may show multiple organisms. Common aerobic organisms are P.aeruginosa, Proteus, Esch. coli and Staph.aureus, while anaerobes include Bacteroides fragilis and anaerobic Streptococci.

This study deals with the bacteriological study of Chronic Suppurative Otitis Media to identify and categorize various organisms isolated and to evaluate their sensitivity pattern.

MATERIALS AND METHODS: The present prospective study was carried out on 50 patients presenting with Chronic Suppurative Otitis Media between January 2014 to December 2014 in the department of E.N.T, Basaveshwara Medical College Hospital and Research Centre, Chitradurga. 


\section{ORIGINAL ARTICLE}

Medical history was recorded in detail including ear discharge, loss of hearing, tinnitus, vertigo, headache, earache, constitutional disturbances and symptoms indicative of intra-cranial complications. The previous history of upper respiratory tract infection, ear-surgery, ear-trauma, nasal allergy, chronic tonsillitis was recorded. Any systemic illness like tuberculosis etc. was also noted. Thorough General Physical Examination and E.N.T Examination was carried out.

Inclusion Criteria: The patients with active aural discharge belonging to all age, sex, religion and socio-economic class were included in the study.

Exclusion Criteria: The patients with history of using antibiotic either systemic or topical (In the form of ear drops) for last 7 days were excluded from the study.

The samples of ear-discharge to be sent for culture and sensitivity were collected from discharging ear under strict aseptic precautions. The swabs were taken before the commencement of antibiotic treatment so as to prevent antibiotics from affecting the potential growth of the organisms.

The external ear canal was cleaned off debris with sterile swabs (soaked in sterile physiological saline) prior to collecting the ear-discharge. The ear-discharge from each patient was collected by inserting swab via sterilized aural speculum and the samples were taken and sent to the laboratory without delay in processing.

The swabs were plated on Nutrient Agar, Blood Agar and Mac Conkey Agar, for determination of culture of microorganisms and determination of their sensitivity in the Department of Microbiology. Antimicrobial susceptibility of the bacterial isolates to the commonly used antibiotics was done by Kirby-Bauer disc diffusion method.

RESULTS AND OBSERVATIONS: Out of the 50 cases examined in the present study, 29(58\%) were males and 21(42\%) were females. The above table shows that Chronic Suppurative Otitis Media was more common in males as compared to females. (Fig. 1)

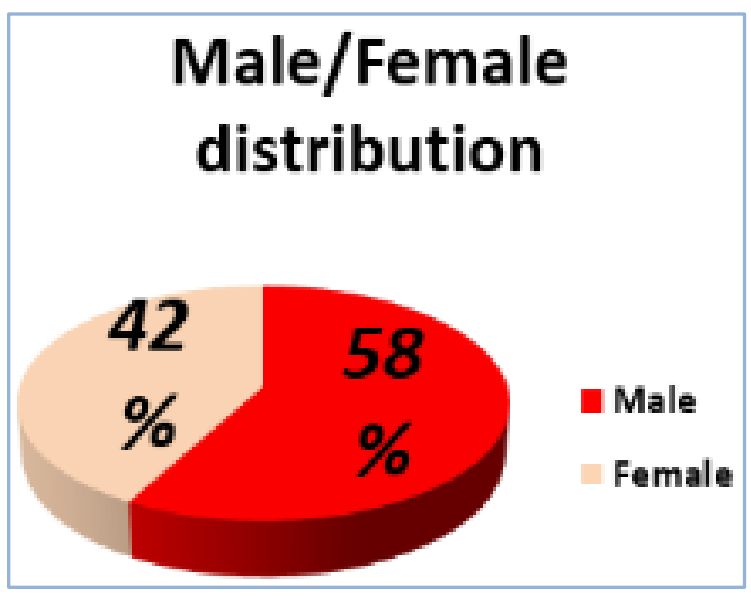

Fig. 1: Male to Female Distribution

The patients in the age group of 21-30 yrs. were more affected (34\%) with Chronic Supprative Otitis Media, followed by the cases in the age group of 11-20 yrs. (26\%). (Fig. 2) 


\section{ORIGINAL ARTICLE}

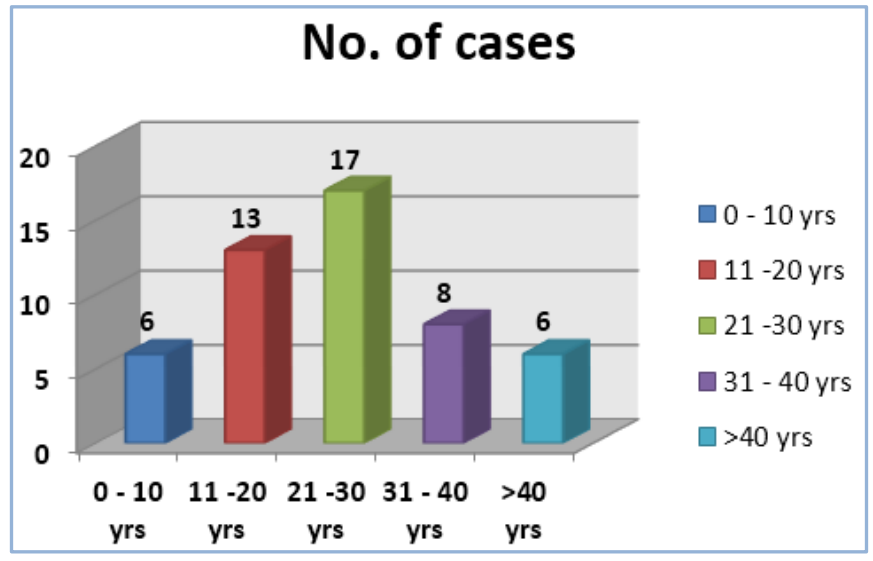

Fig. 2: Age-wise Distribution of Cases

$36(72 \%)$ cases were from rural areas and 14(28\%) cases were from urban areas showing that Chronic Suppurative Otitis Media was more common in people of rural areas as compared to that of urban areas. (Table 1)

\begin{tabular}{|c|c|c|}
\hline Locality & No. of. Cases & Percentage \\
\hline Rural & 36 & $72 \%$ \\
\hline Urban & 14 & $28 \%$ \\
\hline Total & $\mathbf{5 0}$ & $\mathbf{1 0 0} \%$ \\
\hline
\end{tabular}

Table 1: Rural/Urban Distribution of cases

Out of the 50 cases examined, all the cases having otorrhoea were included, $46(92 \%)$ with hearing loss, $39(78 \%)$ with otalgia, 36(72\%) with tinnitus, $26(52 \%)$ with headache and $10(20 \%)$ with vertigo. Facial nerve paresis was only in $1(2 \%)$ case. (Fig. 3 )

Figure 3: Presenting Symptoms in 50 Cases of Chronic Suppurative Otits Media.

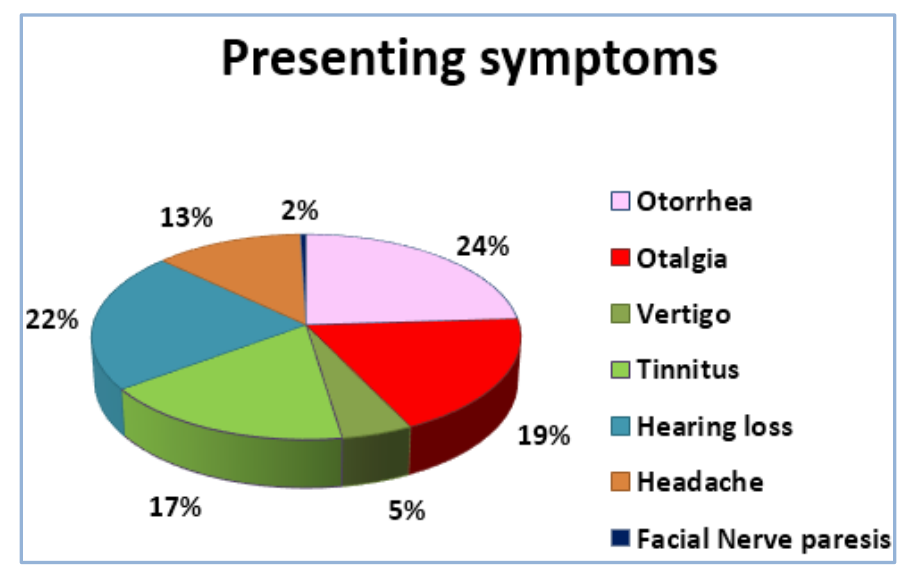

\section{Figure 3}




\section{ORIGINAL ARTICLE}

Tubo-tympanic type of Chronic Suppurative Otitis Media was more common (76\%) than Attico-antral type (24\%) in this study. (Table 2)

\begin{tabular}{|c|c|c|}
\hline $\begin{array}{c}\text { Type of Chronic } \\
\text { Suppurative Otitis Media }\end{array}$ & No. of. Cases & Percentage \\
\hline Tubo-tympanic & 38 & $76 \%$ \\
\hline Attico-antral & 12 & $24 \%$ \\
\hline Total & $\mathbf{5 0}$ & $\mathbf{1 0 0} \%$ \\
\hline
\end{tabular}

Table 2: Type of Chronic Suppurative Otitis Media in 50 cases

The most common bacteria in Chronic Suppurative Otitis Media in this study was Pseudomonas aeruginosa (62\%) followed by Staphylococcus aureus (22\%) and Coagulase negative Staphylococcus (12\%). Proteus vulgaris and Citrobacter sp. were isolated only in $2 \%$ cases each. (Fig. 4)

Figure 4: Bacteriological Profile of Chronic Suppurative Otitis Media.

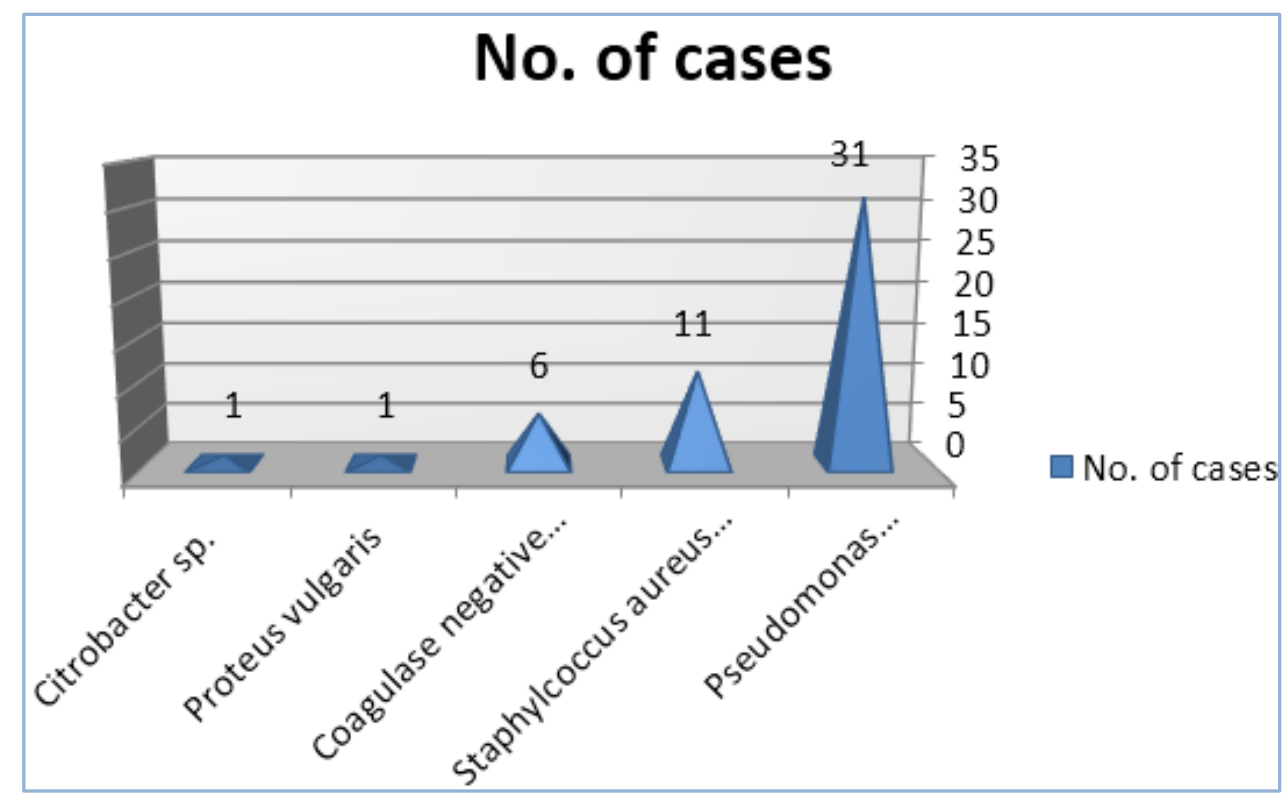

Figure 4

Tubo-tympanic type of Chronic Suppurative Otitis Media was most commonly caused by Pseudomonas aeruginosa whereas Attico-antral type was most commonly caused by Staphylococcus aureus (Coagulase positive). (Fig. 5) 


\section{ORIGINAL ARTICLE}

Figure 5: Comparative bacteriological profile in Tubo-tympanic and Attico-antral type of Chronic Suppurative Otitis Media.

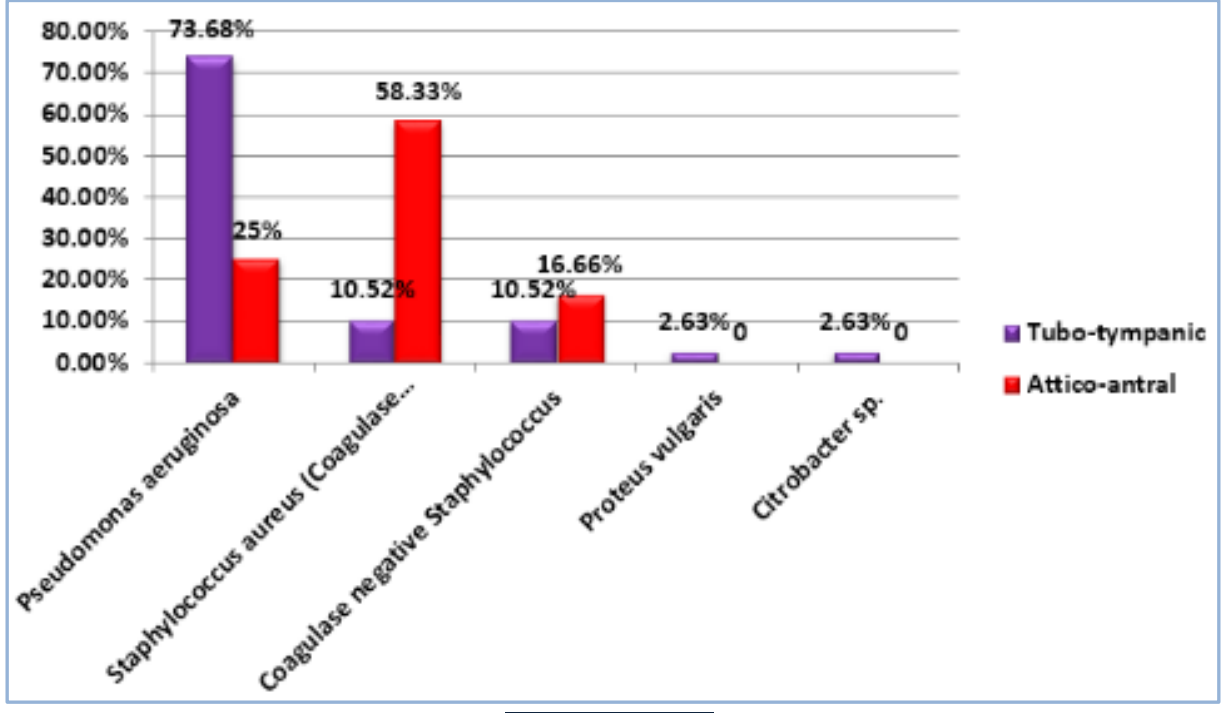

\section{Figure 5}

Gentamicin was the most sensitive (100\%) antibiotic against Pseudomonas aeruginosa followed by Amikacin (96.77\%), Ciprofloxacin (77.41\%), Cefotaxime (54.83\%), Ceftazidime (38.7\%), Ceftriaxone (29.03\%) and Ceftazidime+Clavulanic acid (19.35\%). Pseudomonas aeruginosa was $100 \%$ resistant to Amoxicillin and Co-Amoxyclav. (Fig. 6)

Figure 6: Antibiotic susceptibility of Pseudomonas aeruginosa.

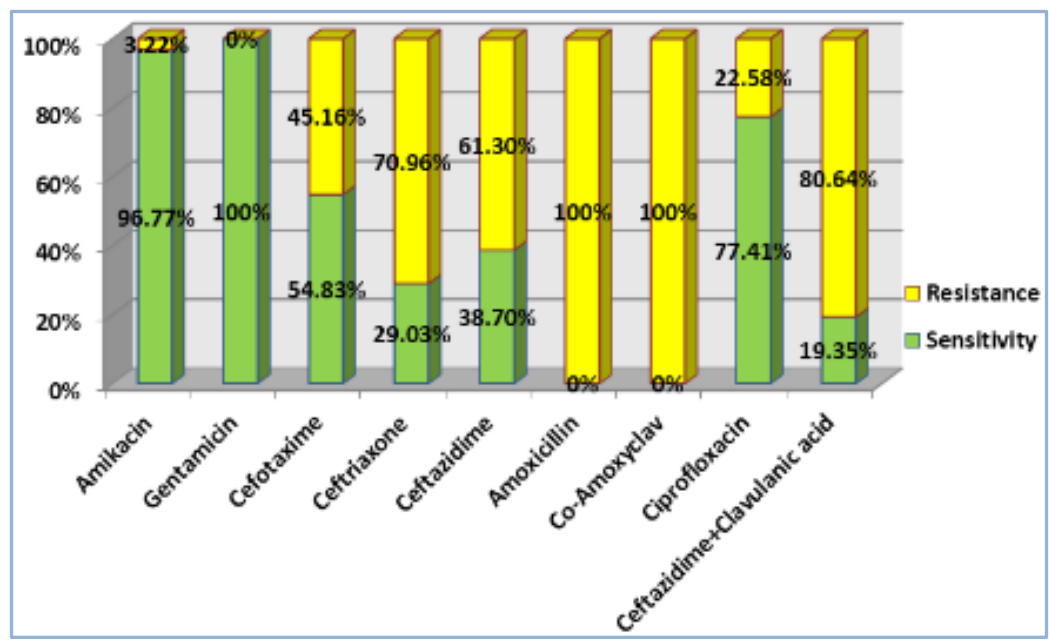

\section{Figure 6}

Ceftriaxone and Gentamicin were the most sensitive (100\%) antibiotic against Staphylococcus aureus followed by Amikacin (90.9\%), Cefotaxime (81.81\%), Co-Amoxyclav (72.72\%), Amoxicillin (54.54\%) and Ceftazidime+Clavulanic acid (54.54\%). Staphylococcus aureus was $72.72 \%$ resistant to both Ceftazidime and Ciprofloxacin in this study. (Fig. 7) 


\section{ORIGINAL ARTICLE}

Figure 7: Antibiotic susceptibility pattern of Staphylococcus aureus.

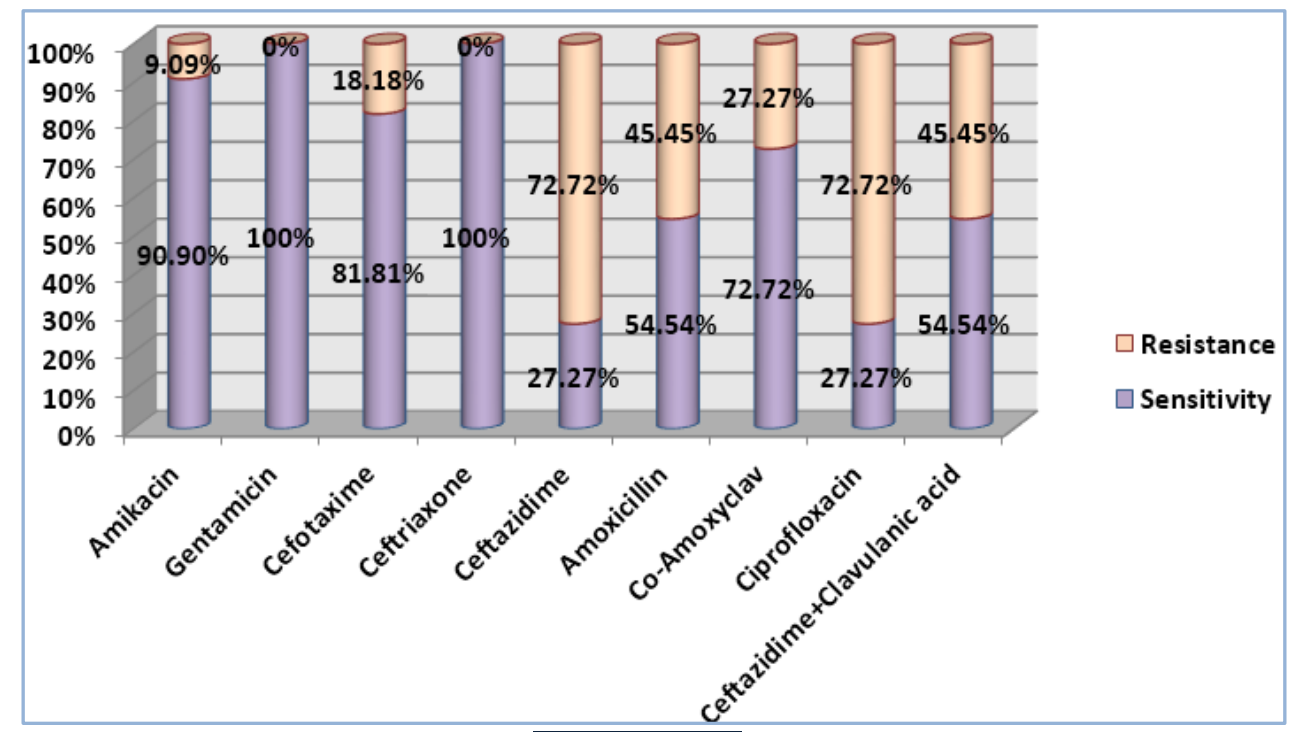

Figure 7

Amikacin and Gentamicin were the most sensitive (100\%) antibiotic against Coagulase negative Staphylococcus, followed by Ceftriaxone (83.33\%) and Ciprofloxacin (33.33). Coagulase negative Staphylococcus was $100 \%$ resistant to Amoxicillin, Co-Amoxyclav, Cefotaxime and Ceftazidime+Clavulanic acid in this study. (Fig. 8)

Figure 8: Antibiotic susceptibility pattern of Coagulase negative Staphylococcus.

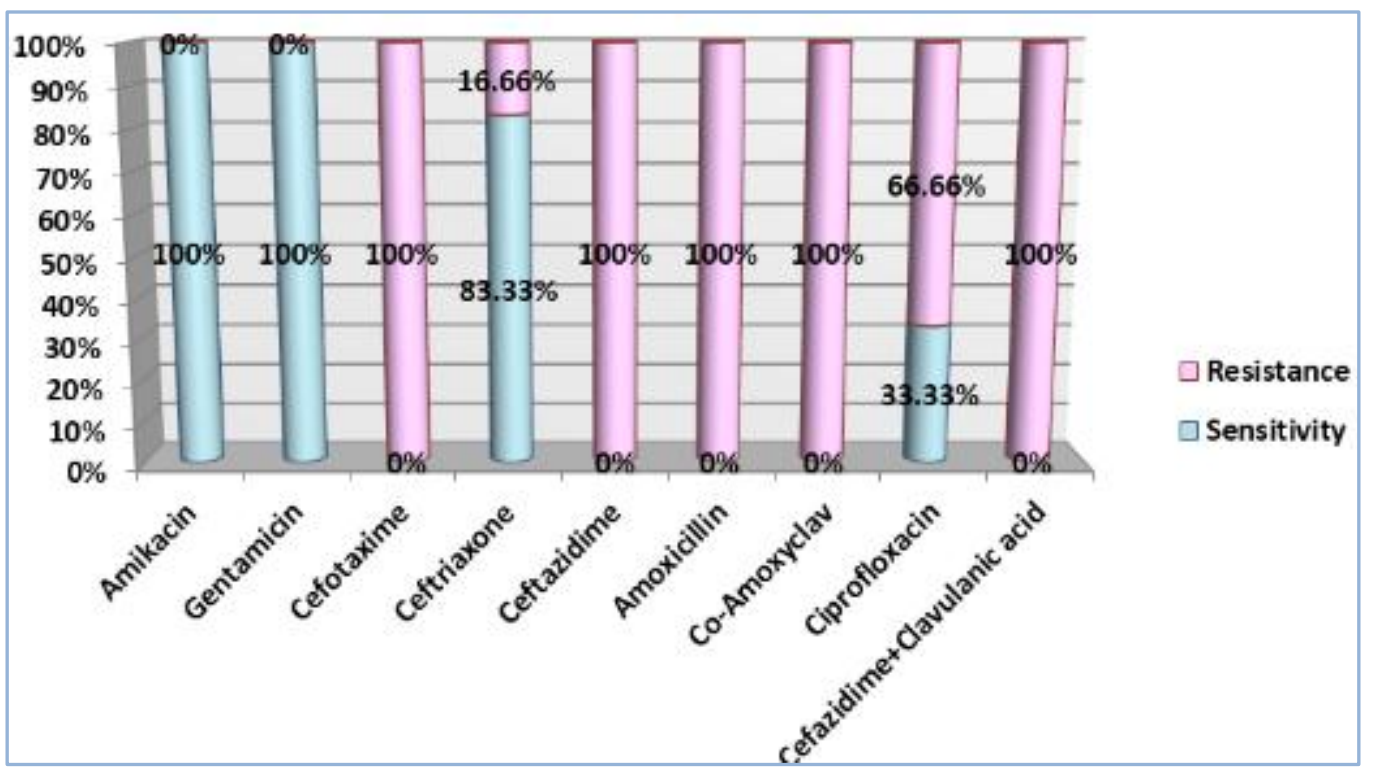

\section{Figure 8}

DISCUSSION: Chronic Suppurative Otitis Media (CSOM) is a condition of the middle ear that is characterized by persistent or recurrent discharge through a chronic perforation of the tympanic membrane from the middle ear cleft. 
Micro-organisms reach middle ear either by passing through the lumen of Eustachian tube from nasopharynx, blood stream from a distant organ having sepsis or via external auditory canal as external contaminants. Infection of the middle ear mucosa subsequently results in ear discharge.

Untreated cases of Chronic Suppurative Otitis Media can result in a broad range of complications. These may be related to the spread of bacteria to structures adjacent to the ear or to local damage in the middle ear itself. Such complications range from persistent otorrhoea, mastoiditis, labyrinthitis, facial nerve paralysis to more serious intracranial abscesses or thrombosis.

While the incidence of such complications is low, these need to be borne in mind when faced by a patient with active Chronic Suppurative Otitis Media. Hence, the treatment needs to be instituted early and effectively to avoid such complications.

Selection of any antibiotic is influenced by its efficacy, resistance of bacteria, safety and risk of toxicity.

In the present study an attempt is made to know the aerobic bacteriology of Chronic Suppurative Otitis Media, with antimicrobial susceptibility testing of the bacterial isolates. The results are compared with the other studies and discussed as follows.

Chronic Suppurative Otitis Media was found to be more common in males, as also observed by Goyal et al. (2009). ${ }^{1}$

The cases in the age group of 21-30 yrs. were more affected (34\%) with Chronic Suppurative Otitis Media, followed by the cases in the age group of 11-20 yrs. (26\%). These findings differ from those of Maji et al. (2007). ${ }^{2}$ and Goyal et al. (2009). ${ }^{1}$ who observed that the majority of cases belongs to age group of 10-20 years.

The present study shows that active infection in Chronic Suppurative Otitis Media is mainly due to Pseudomonas aeruginosa (62\%) followed by Staphylococcus aureus (22\%). This is in accordance with the study done by Kulkarni et al. (1993), Greval et al. (1996), Loy et al. (2002), Ahmed et al.(1999) , Attallah et al. (2000), Khanna et al. (2000), Maji et al. (2007), Alsaimary et al. (2010), and Sharma et al. (2010).2,3,4,5,6,7,8,9,10

Tubo-tympanic type of Chronic Suppurative Otitis Media was most commonly caused by Pseudomonas aeruginosa whereas Attico-antral type was most commonly caused by Staphylococcus aureus (Coagulase positive) in the present study.

Pseudomonas aeruginosa was most sensitive to Gentamicin (100\%) followed by Amikacin (96.77\%), Ciprofloxacin (77.41\%) and Cefotaxime (54.83\%).

Staphylococcus aureus was most sensitive to Ceftriaxone and Gentamicin (100\%) followed by Amikacin (90.9\%), Cefotaxime (81.81\%) and Co-Amoxyclav (72.72\%).

These findings are in accordance with those of Maji et.al (2007), ${ }^{2}$ who concluded in their study that the most effective antibiotic was Amikacin, followed by Gentamicin and Cefotaxime for Pseudomonas aeruginosa and Staph. aureus. Rao et al. (1991). ${ }^{11}$ concluded that Gentamicin still formed the drug of choice in treating the causative strains of either Gram positive or Gram negative bacteria in Chronic Suppurative Otitis Media.

The present findings differ from the findings of Madana et al. (2011).12 in which $100 \%$ of Pseudomonas aeruginosa isolates showed susceptibility to Ceftazidime and $92 \%$ of isolates showed susceptibility to Ciprofloxacin. Goyal et al. (2009). ${ }^{1}$ concluded in their study that the most effective antibiotic in Chronic Suppurative Otitis Media was Imipenem (97.5\%), followed by Piperacillin (92.6\%) and Ceftazidime (91.5\%). 
The present study shows that Pseudomonas aeruginosa was $100 \%$ resistant to both Amoxicillin and Co-Amoxyclav and Staphylococcus aureus was $72.72 \%$ resistant to both Ceftazidime and Ciprofloxacin.

Coagulase negative Staphylococcus was isolated in $12 \%$ cases in this study whereas Pealskulrat et al. (2009). ${ }^{13}$ Found Coagulase negative Staphylococcus in $10.1 \%$ cases.

Coagulase negative Staphylococcus was most sensitive to Amikacin (100\%) and Gentamicin (100\%) followed by Ceftriaxone (83.33\%) and 100\% resistant to Amoxicillin, Co-Amoxyclav, Cefotaxime and Ceftazidime+Clavulanic acid. These findings differ from those of Goyal et al. (2009).1 who observed that Coagulase negative Staphylococcus was sensitive to Amikacin in $77.4 \%$ isolates and to Gentamicin in only $63.3 \%$ isolates.

This study points out emergence of resistance of micro-organisms causing Chronic Suppurative Otitis Media against various antibiotics because of their indiscriminate use, over the counter prescription, or their over dose.

CONCLUSION: Chronic Suppurative Otitis Media can cause marked hearing loss which has a negative impact on the development of speech, language and social interaction as well as school or work place performance. Changes in the microbiological flora following the advent of antibiotics with high efficacy increase the relevance of reappraisal of the modern day flora in Chronic Suppurative Otitis Media and their in-vitro antibiotic sensitivity pattern is very important for the clinician to plan a systemic outline of treatment for a patient with a chronically discharging ear.

The consequences of the use of antibiotics prescribed indiscriminately are the failure of treatment, emergence of resistant strains of organisms, intra-cranial and extra-cranial complications, enhancing the treatment costs and sufferings. Hence, the knowledge of common causative organisms and their antibiotic sensitivity is helpful in deciding the treatment of these patients.

\section{REFERENCES:}

1. Goyal R., Aher A., De S. and Kumar A. (2009) Chronic Suppurative Otitis Media-A clinico microbiological study, Indian Journal of Otology: 15; 18-22.

2. Maji P.K. and Chatterjee T. K. (2007) The investigation of bacteriology of Chronic Suppurative Otitis Media in patients attending a tertiary care hospital with special emphasis on seasonal variation, Indian J. Otolaryngology \& Head and Neck Surgery-: 59; 128-31.

3. Kulkarni R.D., Dharmadhikari C. A., Kulkarni V.A., U. S. Udgaonkar U. A. and Pawar S. G. (1993) Bacteriological study of Chronic Otitis media, Indian Journal of Otolaryngology and Head and Neck Surgery: 2 (2); 110-112.

4. Greval R. S. (1996) Bacteriological patterns of chronic suppurative otitis media in Ludhiana, Indian Journal of Medical Sciences: 50 (6); 192-195.

5. Loy A.H.C., Tan A. L. and Lu P. K. S. (2002) Microbiology of Chronic Suppurative Otitis Media in Singapore, Singapore Med. Journal: 43(6); 296-299.

6. Ahmed A., Usman J., Hashim R. (1999) Isolates from Chronic Suppurative Otitis Media and their Antimicrobial Sensitivity, Pak Armed Forces Med J: 49(2); 82-5.

7. Attallah M.S.W. (2000) Microbiology of Chronic Suppurative Otitis Media with Cholesteatoma, Saudi Med. Journal: 21; 924-927.

8. Khanna V.,Chander J., Nagarkar N.M. and Dass A. (2000) Clinico-microbiological evaluation of Active Tubotympanic Type Chronic Suppurative Otitis Media, J. Otolaryngol: 29(3); 148-53. 


\section{ORIGINAL ARTICLE}

9. Alsaimary I. E., Alabbasi A. M. and Najim J. M. (2010) Antibiotics susceptibility of bacterial pathogens associated with otitis media, Journal of Bacteriology Research: 2(4); 41-50.

10. Sharma K., Aggarwal A., and Khurana P. S. (2010) Comparison of bacteriology in bilaterally discharging ears in chronic suppurative otitis media, Indian Journal of Otolaryngology and Head and Neck Surgery: 62 (2);153-157.

11. Rao B. N. and Reddy M. S. (1994) Chronic Suppurative Otitis Media- A prospective study, Indian Journal of Otolaryngology and Head and Neck Surgery: 3(2); 72-77.

12. Madana J., Yolmo D., Kalaiarasi R., Gopalakrishnan S. and Sujatha S. (2011) Microbiological profile with antibiotic sensitivity pattern of cholesteatomatous chronic suppurative otitis media among children, International Journal of Pediatric Otorhinolaryngology, Article in Press.

13. Pealskulrat B. (2010) Bacteriology of Chronic Suppurative Otitis Media, Mahasarakham Hospital Journal, Thailand: 6 (4).

\section{AUTHORS:}

1. Mahesh V. Kattimani

2. Shweta Anand

\section{PARTICULARS OF CONTRIBUTORS:}

1. Assistant Professor, Department of ENT, Basaveshwara Medical College Hospital and Research Centre, Chitradurga.

2. Assistant Professor, Department of ENT, Basaveshwara Medical College Hospital and Research Centre, Chitradurga.

\section{FINANCIAL OR OTHER} COMPETING INTERESTS: None

\section{NAME ADDRESS EMAIL ID OF THE} CORRESPONDING AUTHOR:

Dr. Mahesh V. Kattimani, \# 3/1024, Turuvannur Road, Near Reddy Kalyana Mantapa, Chitradurga-577501, Karnataka, India.

E-mail: magz0705@gmail.com

Date of Submission: 04/08/2015. Date of Peer Review: 05/08/2015. Date of Acceptance: 17/08/2015. Date of Publishing: 19/08/2015. 